\title{
DOE Bioenergy Center Special Issue: The Great Lakes Bioenergy Research Center (GLBRC)
}

\author{
Michael D. Casler
}

Published online: 7 February 2010

(C) Springer Science+Business Media, LLC. 2010

Keywords Bioenergy centers · US Department of Energy

This issue of BioEnergy Research is the second of three special issues to feature work from the US Department of Energy Bioenergy Centers. This special issue is focused on research supported by the Great Lakes Bioenergy Research Center (GLBRC). Research originating from the Bioenergy Sciences Center was published in BioEnergy Research Volume 2, Issue 4, 2009. Research originating from the Joint BioEnergy Institute will be published later in BioEnergy Research Volume 3, 2010.

As described by Slater et al. (pp. 3-5), GLBRC is a multi-institution consortium based at the University of Wisconsin-Madison, with Michigan State University as the major partner. The GLBRC is divided into four research thrusts that are aimed at modification and deconstruction of plant biomass into soluble sugars, conversion of soluble sugars into liquid fuels, and development of sustainable production systems for plant biomass. The center is also focused on the development of enabling technologies to support the research thrusts, including development of high-throughput transcript, protein, metabolite, and fermentation platforms. Both bioinformatics support for research and participation of researchers in education and outreach are underlying principles that are woven throughout the center. Research of GLBRC is focused largely on bioenergy production systems of the central USA, surrounding the

M. D. Casler $(\bowtie)$

USDA-ARS, US Dairy Forage Research Center,

1925 Linden Dr.,

Madison, WI 53706-1108, USA

e-mail: michael.casler@ars.usda.gov
Great Lakes region, and based largely on native prairie plants, maize stover, and model species. The articles in this special issue are a sample of research from all four of the research thrusts plus the enabling technologies group.

The focus of GLBRC on promotion, development, and maintenance of biological diversity across the agricultural landscape used for bioenergy feedstock production is illustrated by two articles that represent the research theme, "Development of a sustainable bioenergy economy." Landis et al. (pp. 6-19) examine abundance and diversity of beneficial insects, including bees, beetles, and flies, in relation to species-richness of cellulosic biofuel crops. Jesus et al. (pp. 20-27) describe bacterial communities in the rhizosphere of several biofuel crops and identify plant community and soil physical factors related to abundance and diversity of bacterial phyla.

The GLBRC has made a major commitment to improving plant biomass for conversion to liquid fuels. These efforts include development and modification of pathways to increase energy-rich hydrocarbons in plant tissues and to create plant cell walls that are more easily deconstructed into component sugars. Three articles of this special issue represent the research theme, "Improved plant biomass." de Leon et al. (pp. 28-37) describe natural genetic variation within maize for fiber characteristics of various plant parts and their potential value as selection criteria in breeding maize for reduced cell-wall recalcitrance. Casler (pp. 47-54) describe efforts to breed switchgrass for increased biomass yield, illustrating the potential for breeding progress that exists within natural populations of this species. Finally, Schwartz et al. (pp. 38-46) describe genetic variability for flowering time in Brachypodium distachyon, a model grass species that is under development as a model plant for studying physiology, genetics, and genomics of perennial cellulosic grasses for 
biofuel production. These three studies are only a sample of the research within GLBRC that attempts to capitalize on natural genetic mutations to create more suitable feedstocks and methods for deconstructing their hydrocarbons into liquid fuels.

The GLBRC is exploring innovative solutions to easily convert plant-derived compounds into bioenergy compounds. The research theme, "Bioconversion" is represented by the article of Noguera et al. (pp. 55-66), in which the authors use a genetic mutant of Rhodobacter sphaeroides to study electron partitioning from nutrients into hydrogen gas. Improvements in efficiency of bioconversion processes are being investigated within GLBRC using natural genetic variation, targeted mutations, and functional and comparative genomics methodologies to identify unique stress adaptations, enzymologies, and conversion properties in a wide range of organisms and biological systems.

The development of efficient and economical biomass processing technologies will require significant improvements in the properties and cocktails of enzymes used to convert plant biomass into liquid fuels, represented in GLBRC by the research theme, "Biomass processing." In their review, Bannerjee et al. (pp. 82-92) describe many of the current impediments to bioconversion and the GLBRC approaches that include bioprospecting for superior key enzymes, protein engineering, high-level expression in plants, and synthetic enzyme cocktails. More specifically, Gao et al. (pp. 67-81) report research results of enzyme cocktails that include fungal cellulases and bacterial hemicellulases and their effect on bioconversion of maize stover.

Finally, the enabling technologies group of GLBRC describes the development and implementation of a highthroughput platform to provide key phenotypic measurements in support of research projects throughout GLBRC (Santoro et al., pp. 93-102). This high-throughput technology to rapidly assay important plant traits and bioconversion efficiencies on thousands of plant samples will be an essential element to support each of the four research themes of GLBRC.

I would like to thank a total of 21 anonymous reviewers for their contributions to this special issue of BioEnergy Research, especially those for whom I requested unreasonably short turnaround times due to our very tight deadlines. 